\title{
THE SENSITIVITY OF C-BAND HYBRID POLARIMETRIC RISAT-1 SAR DATA TO LEAF AREA INDEX OF PADDY CROP
}

\author{
Hari Shanker Srivastava ${ }^{1,}{ }^{*}$, Thota Sivasankar ${ }^{1}$, Parul Patel ${ }^{2}$ \\ ${ }^{1}$ Indian Institute of Remote Sensing, Dehradun, India - hari.isro@ gmail.com, siva.iirs@ gmail.com \\ ${ }^{2}$ Space Applications Centre, Ahmedabad, India - parul@sac.isro.gov.in
}

Commission V, SS: Natural Resources Management

KEY WORDS: Hybrid polarimetry, $\mathrm{m}-\delta, \mathrm{m}-\chi$ and $\mathrm{m}-\alpha$ space decompositions, Leaf area index (LAI), Paddy, RISAT-1 SAR

\begin{abstract}
:
Active microwave remote sensing data has become an important source to retrieve crop biophysical parameters due to its unique sensitivity towards geometrical, structural and dielectric properties of various crop components. The temporal variability of various crop biophysical parameters during crop cycle has significant impact on the overall crop yield. In this study, two RISAT-1 hybrid polarimetric temporal SAR datasets at $\sim 32^{\circ}$ incidence angle were acquired during 2015 Kharif season. The in-situ leaf area index (LAI) values from seventeen paddy fields were measured in synchrony to the satellite passes during both the campaigns. Analysis observed the decreasing trend of backscattering coefficients $\left(\sigma^{\circ} \mathrm{RH}, \sigma^{\circ} \mathrm{RV}\right)$ with increase in LAI. Results indicate that the sensitivity of hybrid polarimetric parameters towards LAI, also depends on the change in crop structure due to crop growth. This study investigate the sensitivity of backscattering coefficients $\left(\sigma^{\circ} \mathrm{RH}, \sigma^{\circ} \mathrm{RV}\right)$ and polarimetric parameters (even bounce, odd bounce and volume component) generated from $\mathrm{m}-\delta, \mathrm{m}-\chi$ and $\mathrm{m}-\alpha$ space decompositions towards LAI using empirical analysis. An increase of 0.16 in $\mathrm{R}^{2}$ (from 0.63 to 0.79 ) clearly indicates that the polarimetric parameters (even bounce, odd bounce and volume component) are more sensitive to LAI of paddy crop than the backscattering coefficients $\left(\sigma^{\circ}{ }_{\mathrm{RH}}, \sigma^{\circ} \mathrm{RV}\right)$. It has been identified that the combined use of backscattering coefficients as well as polarimetric parameters (even bounce, odd bounce and volume component) in the model, can significantly improve the accuracy of the LAI estimation.
\end{abstract}

\section{INTRODUCTION}

Agricultural target parameters such as crop biophysical parameters and underneath soil moisture are highly dynamic in spatial as well as temporal. Leaf area index (LAI) is an important crop biophysical parameter, which indicates the relative amount of total area exposed and active leaves to the solar radiation (Ulaby et al., 1984). The temporal variability of LAI during the whole crop cycle plays an important role on overall crop yield (Dale, 1977; Clevers \& Leeuwen, 1996). Remote sensing data has become primary source for agricultural crop studies by providing images with high spatial and temporal resolution from local to global scales. Synthetic aperture radar (SAR) based remote sensing data has been suggested for uninterrupted paddy crop growth monitoring due to its independent from cloud cover and solar illumination (Chakraborty et al., 2005). Due to its unique sensitivity towards geometrical, structural and dielectric properties of the target and independent from cloud cover, SAR data has been used in various domains including agriculture (Patel et al., 2006; Srivastava et al., 2003), forestry (Srivastava et al., 2007; Luckman et al., 1997) and wetland (Brisco et al., 2015; Patel et al., 2009).*

The radar return signal from an agricultural target is also depends on the SAR sensor parameters like frequency, incidence angle and polarization (Baghdadi et al., 2009; Inoue et al., 2014). Paloscia (1998) has investigated the sensitivity of the backscattering coefficients at P-, L- and C-bands to LAI of broad leaf crops and narrow leaf crops. Study has concluded

\footnotetext{
${ }^{*}$ Corresponding author
}

that the P- \& C-bands may be helpful for narrow leaf crops and L-band is highly sensitive for broad leaf crops mainly in HV polarisation. Macelloni et al., (2001) has analyzed the influence of the plant geometry on the backscattering coefficients using multi-frequency (C- and L-bands) multi-temporal SAR polarimetric data acquired from airborne and space borne SAR sensors. Results have indicated that the relationship between the backscattering coefficient and LAI is influenced by the geometry of plants. It was also observed that the decreasing trend with increase in LAI for narrow leaf crops, whereas the trend is quite opposite for broad leaf crops. Inoue et al., (2002) study has found that the LAI of paddy crop is highly correlated with the C-band in $\mathrm{HH}$ - and cross polarizations (HV/VH). It is also identified that the high frequency signals at high incidence angles are sensitive enough to detect thin rice seedlings just after transplant.

Most of the previous investigations for crop biophysical parameters retrieval have been carried using SAR data acquired by illuminating linear horizontal/vertical polarized signals. The recent advancement of hybrid polarimetry architecture in SAR technologies, which transmits circular polarized signal and receives coherent linear orthogonal horizontal and vertical polarized signals, has resolved several technical and maintenance hurdles in linear polarimetry (Freeman \& Saatchi 2004; Turkar et al., 2013). RISAT-1 is the first space borne earth observation satellite with hybrid polarimetry architecture, launched by Indian Space Research Organization (ISRO) on April 26, 2012. After the successful launch of RISAT-1, researchers from world-wide showed keen interest to investigate the hybrid polariemetric SAR data for various remote sensing applications to make use of the advantages over linear polarimetry (Dabboor et al., 2015; Sivasankar et al., 2015; Uppala et al., 2015; Li et al., 2015). 
The objectives of this study were to understand the sensitivity of the parameters generated from RISAT-1 hybrid polarimetric SAR data towards LAI of paddy crop, to investigate the potential of backscattering coefficients $\left(\sigma^{\circ}{ }_{\mathrm{RH}}, \sigma^{\circ}{ }_{\mathrm{RV}}\right)$ and polarimetric parameters (even bounce, odd bounce and volume component) for LAI estimation. Since the hybrid polarimetry is relatively new remote sensing technology and also a limited research work has been done so far over this dataset for biophysical parameters retrieval, results of this study can help to understand the interaction of circular polarized signal with paddy crop at different growing stages.

\section{MATERIALS AND METHODS}

\subsection{Study area and datasets}

Since high incidence angle SAR data is more sensitive to the agricultural crop characteristics, Two RISAT-1 hybrid polarimetric SAR datasets were acquired at $32^{\circ}$ incidence angle over parts of Haridwar district, India during 2015. Study area is usually dominated with paddy and sugarcane crops during kharif season. The monsoon season in this study area is from July to September and the highest rainfall noticed in the August month. The detailed specifications of SAR sensor parameters at the time of acquisition and SAR data are given in the Table 1 . Since the sensor parameters are same during the both campaigns, the changes in the sensitivity of parameters generated from RISAT-1 hybrid polarimetric SAR data towards LAI of paddy crop were considered it as caused by the crop growth.

Table 1. Specifications of SAR data and sensor parameters used in this study

\begin{tabular}{|l|l|l|}
\hline DATE OF PASS & $\begin{array}{l}16 \text { August } \\
2015\end{array}$ & $\begin{array}{l}10 \text { September } \\
2015\end{array}$ \\
\hline SATELLITE & RISAT-1 & RISAT-1 \\
\hline PLATFORM & Space borne & Space borne \\
\hline MODE & FRS-1 & FRS-1 \\
\hline BAND/SENSOR & C/SAR & C/SAR \\
\hline POLARIZATION & RH/RV & RH/RV \\
\hline $\begin{array}{l}\text { CENTRAL } \\
\text { INCIDENCE ANGLE }\end{array}$ & $\sim 32^{\circ}$ & $\sim 32^{\circ}$ \\
\hline $\begin{array}{l}\text { AZIMUTH } \\
\text { RESOLUTION }\end{array}$ & 3 & 3 \\
\hline $\begin{array}{l}\text { RANGE } \\
\text { RESOLUTION }\end{array}$ & 2 & 2 \\
\hline
\end{tabular}

\subsection{Hybrid polarimetric parameters}

2.2.1 Backscattering coefficients: The generation of backscattering coefficients from digital number (DN) image is the primary step for any analysis using SAR data. Backscattering coefficients $\left(\sigma^{\circ}{ }_{\mathrm{RH}}, \sigma^{\circ} \mathrm{RV}\right)$ represent the intensity of the signal that returned to the SAR sensor in H-Horizontal and V-Vertical polarizations by illuminating R-Right circular polarized signal. The SAR data was radiometrically calibrated using the following equation as given by Patel et al., (2014).

$\sigma_{(d B)}^{o}=10 \times \log _{10}\left(\frac{D N_{i}^{2}}{C_{i i}}\right)+10 \times \log _{10}\left(\frac{\sin \left(\theta_{i}\right)}{\sin \left(\theta_{\text {center }}\right)}\right)$ of $\mathrm{i}^{\text {th }}$ pixel and $\theta_{\text {center }}$ is central incidence angle.

2.2.2 Stokes parameters:Stokes (1852) defined a set of four parameters based on two linear orthogonal polarization signals (horizontal and vertical) to describe the polarization state of the electromagnetic signal. These parameters were used to analyze the return signal from the agricultural target by illuminating right circular polarized signal. The Stokes parameters were generated using following equation.

$g=\left[\begin{array}{l}g_{0} \\ g_{1} \\ g_{2} \\ g_{3}\end{array}\right]=\left[\begin{array}{c}\left\langle\left|E_{R H}\right|^{2}+\left|E_{R V}\right|^{2}\right\rangle \\ \left\langle\left|E_{R H}\right|^{2}-\left|E_{R V}\right|^{2}\right\rangle \\ 2 \times R e\left\langle E_{R H} E_{E V}^{*}\right\rangle \\ -2 \times \operatorname{Im}\left\langle E_{R H} E_{E V}^{*}\right\rangle\end{array}\right]$

Here, $\mathrm{E}$ is the complex backscattered electric field, $|\ldots|$ denotes absolute value, $\langle\ldots\rangle$ represents average, * indicates complex conjugate and Re \& Im denotes the real and imaginary parts of the complex respectively.

2.2.3 $\mathbf{m}-\boldsymbol{\delta}$ decomposition: In this decomposition, it has been considered that degree of polarization $(\mathrm{m})$ as prime variable and phase difference between received horizontal \& vertical polarized signals $(\delta)$ as second variable. The un-polarized portion in the return signal is considered as the volume component. However, the polarized portion of the return signal is sub divided into even bounce and odd bounce components using $\delta$. The equations used to generate $\mathrm{m}, \delta$ are given below.

$m=\frac{\sqrt{g_{1}^{2}+g_{2}^{2}+g_{3}^{2}}}{g_{0}}$

$\delta=\tan ^{-1}\left(\frac{g_{3}}{g_{2}}\right)$

The formulae for $\mathrm{m}-\delta$ decomposition is given below as proposed by Raney (2007),

Volume component $=\sqrt{(1-m) \times g_{0}}$

(5)

Even bounce $=\sqrt{\frac{m \times g_{0} \times(1-\sin \delta)}{2}}$

Odd bounce $=\sqrt{\frac{m \times g_{0} \times(1+\sin \delta)}{2}}$

2.2.4 m- $\chi$ decomposition: This decomposition technique is developed by Raney et al. (2012) based on " $m$ " and degree of circularity $(\chi)$. The relationship of degree of circularity and the Stokes parameters is given as,

$\sin 2 \chi=\frac{g_{3}}{\left(m \times g_{0}\right)}$

The parameters generated using $\mathrm{m}-\chi$ decomposition is expressed as,

Where, $\mathrm{C}_{\mathrm{ii}}$ is calibration constant, $\theta_{\mathrm{i}}$ represents incidence angle 
Volume component $=\sqrt{(1-m) \times g_{0}}$

Even bounce $=\sqrt{\frac{m \times g_{0} \times(1-\sin 2 \chi)}{2}}$

Odd bounce $=\sqrt{\frac{m \times g_{0} \times(1+\sin 2 \chi)}{2}}$

2.2.5 m- $\alpha$ decomposition: The key inputs for this decomposition are " $\mathrm{m}$ " and polarization angle $(\alpha)$. The polarization angle $(\alpha)$ was derived using the following equation.

$\alpha=0.5 \times \tan ^{-1}\left(\frac{\sqrt{g_{1}^{2}+g_{2}^{2}}}{g_{3}}\right)$

In this technique, the polarized signal is sub divided into even bounce and odd bounce using " $\alpha$ ". However, the volume component is considered as the un-polarized signal portion in the return signal. The $\mathrm{m}-\alpha$ space decomposition has expressed with the following equations,

Volume component $=\sqrt{(1-m) \times g_{0}}$

Even bounce $=\sqrt{\frac{m \times g_{0} \times(1-\cos 2 \alpha)}{2}}$

Odd bounce $=\sqrt{\frac{m \times g_{0} \times(1+\cos 2 \alpha)}{2}}$

\subsection{Ground truth data collection}

The farmers' fields of minimum size, $22 \times 22 \mathrm{~m}^{2}$ were considered as suggested by Patel \& Srivastava (2013) for RISAT-1 FRS- 1 mode by accounting the characteristic-fading phenomenon of SAR signal. The in-situ leaf area index (LAI) values from seventeen of such paddy fields were measured in synchrony to the satellite passes during both the campaigns. The AccuPAR model LP-80 was used to measure in-situ LAI in sequence of two above and five below canopy samples with 5 replications at each field. It has been observed that the increase in LAI from 16th Aug. 2015 to 10th Sep. 2015 due to the crop growth. It is also observed that the plant structure on first campaign was more vertical with hardly horizontal components and on second campaign the plant is also in dominant vertical but the panicles was extended in horizontal direction due to crop growth. The field photos taken on both campaigns are given in Fig. 1 to illustrate the change in crop structure due to the crop growth.

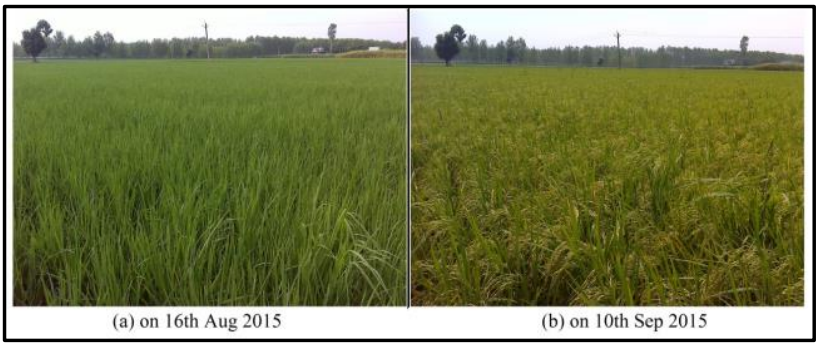

Figure 1. Ground-based photographs of a paddy field taken on 16 August 2015 and 10 September 2015

\section{RESULTS AND DISCUSSION}

The results were analyzed in three phases, first by directly relating the backscattering coefficients $\left(\sigma^{\circ}{ }_{\mathrm{RH}}, \sigma^{\circ} \mathrm{RV}\right)$ with the insitu LAI values, second by sensitivity analysis of polarimetric parameters in two different crop growth stages separately and also combined of both stages and the third phase has made an attempt to investigate the potential of backscattering coefficients $\left(\sigma^{\circ} \mathrm{RH}, \sigma^{\circ} \mathrm{RV}\right)$ and polarimetric parameters (even bounce, odd bounce and volume component) generated from $\mathrm{m}-\delta, \mathrm{m}-\chi$ and $m-\alpha$ space decompositions for LAI estimation using empirical analysis. A significant variability in sensitivity of parameters generated from hybrid polarimetric RISAT-1 SAR data towards LAI was observed during the paddy growth stage changes from booting to grain filling, because of change in crop structure due to the crop growth.

\subsection{Relationship between backscattering coefficients and LAI}

A clear decreasing trend of backscattering coefficients $\left(\sigma^{\circ}{ }_{\mathrm{RH}}\right.$, $\sigma^{\circ} \mathrm{RV}$ ) with the in-situ LAI values was observed as anticipated from the past investigations. Macelloni et al., (2001) and Fontanelli et al., (2013) were observed that the radar backscatter increases with increase of biomass of broad leaf crops whereas the backscatter trend is flat or decreasing for narrow leaf crops. This behavior of different backscatter trends from "narrow" and "broad" leaf crops is also confirmed by the theoretical simulations using discrete element radiative transfer model. According to Sati et al., (2012), this trend is caused by the strong absorption of thin and dense vertical stems of narrow leaf crops like paddy, wheat etc. In Fig. 2 , the $\sigma^{\circ}{ }_{\mathrm{RH}}$ and $\sigma^{\circ}{ }_{\mathrm{RV}}$ values from both phenological stages are shown as a function of in-situ LAI.

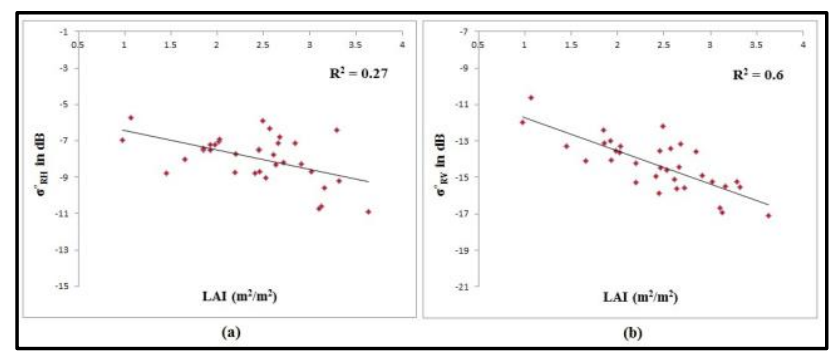

Figure 2. $\sigma^{\circ} \mathrm{RH}$ and $\sigma^{\circ} \mathrm{RV}$ values in $\mathrm{dB}$ at an incidence angle $32^{\circ}$ versus LAI of paddy on 16 August 2015 and 10 September 2015

Since the paddy is a dominant vertically oriented crop, RV polarization has shown a good correlation with the coefficient of determination, $\mathrm{R}^{2}$, of 0.6 . However, the $\mathrm{RH}$ polarization has shown $0.27 \mathrm{R}^{2}$ with LAI. The direct relationship between backscattering coefficients and underneath soil moisture has also been checked and found to be very low. This indicates that the backscattered signal is more sensitive to the crop characteristics than the underneath soil moisture.

During ground truth data collection, it has been observed that the change in plant structure from more vertical during booting stage (on 16 Aug 2015) to the complex structure distributed in both vertical (stem) and horizontal (panicles and bended leaves) directions during grain filling stage (on 10 Sep 2015) due to the crop growth. For an illustration, field photographs taken during both the campaigns were given in Fig 1. To understand the influence of plant structure on the sensitivity of the parameters 
generated from RISAT-1 hybrid polarimetric SAR data towards LAI, detailed analysis was carried separately during both phenological stages and discussed it in the following section.

\subsection{Sensitivity analysis}

In this study, the coefficient of determination $\left(\mathrm{R}^{2}\right)$, has been considered to analyze the sensitivity of parameters generated from RISAT-1 hybrid polarimetric SAR data towards LAI and the calculated values from both phenological stages separately and combined were given in the Table 2 . The variation in the sensitivity of backscattering coefficients $\left(\sigma^{\circ} \mathrm{RH}, \sigma^{\circ}{ }_{\mathrm{RV}}\right)$ towards LAI at two phenological stages of paddy crop has clearly indicates its dependence on the change in plant structure due to crop growth. Since the plant is more vertical during booting stage (on 16 August 2015), RH polarization has shown a very low $\mathrm{R}^{2}$ of 0.04 . And the $\mathrm{R}^{2}$ of $\mathrm{RH}$ polarization on 10 September 2015 has increased to 0.34 , which indicates that the portion of bended panicles is acting as horizontal orientated components. The increase in $\mathrm{R}^{2}$ of $\mathrm{RV}$ polarization from 0.46 to 0.55 when crop phenology changes from booting to grain filling stage, is expected due to increase in average crop height from $0.8 \mathrm{~m}$ to $1.2 \mathrm{~m}$. The range of crop heights that were observed from the sampled seventeen fields during both the ground truth campaigns is given in the Fig 3 .

Table 2. Sensitivity of individual hybrid polarimetric parameters towards LAI

\begin{tabular}{|l|l|l|l|}
\hline Polarimetric & $\begin{array}{l}\mathrm{R}^{2} \text { on 16 } \\
\text { Aug 2015 } \\
(17 \\
\text { samples })\end{array}$ & $\begin{array}{l}\mathrm{R}^{2} \text { on 10 } \\
\text { Sep 2015 } \\
(17 \\
\text { samples })\end{array}$ & $\begin{array}{l}\mathrm{R}^{2} \text { combined } \\
\text { both (34 \#) }\end{array}$ \\
\hline$\sigma^{\circ}$ RH in dB & 0.04 & 0.34 & 0.27 \\
\hline$\sigma^{\circ}$ RV in dB & 0.46 & 0.55 & 0.60 \\
\hline $\mathrm{g}_{0}$ & 0.19 & 0.38 & 0.35 \\
\hline $\mathrm{g}_{1}$ & 0.18 & 0.03 & 0.002 \\
\hline $\mathrm{g}_{2}$ & 0.29 & 0.001 & 0.05 \\
\hline $\mathrm{g}_{3}$ & 0.66 & 0.09 & 0.29 \\
\hline $\mathrm{m}$ & 0.52 & 0.05 & 0.32 \\
\hline delta $(\delta)$ & 0.02 & 0.002 & 0.03 \\
\hline chi $(\chi)$ & 0.61 & 0.06 & 0.2 \\
\hline alpha $(\alpha)$ & 0.07 & 0.02 & 0.02 \\
\hline psi $(\psi)$ & 0.34 & 0.04 & 0.15 \\
\hline Volume & 0.37 & 0.56 & 0.57 \\
\hline m-delta_Even & 0.0004 & 0.13 & 0.08 \\
\hline m-delta_Odd & $5 \mathrm{E}-08$ & 0.22 & 0.06 \\
\hline m-chi_Even & 0.20 & 0.1 & 0.004 \\
\hline m-chi_Odd & 0.21 & 0.28 & 0.24 \\
\hline m-alpha_Even & 0.0001 & 0.17 & 0.08 \\
\hline m-alpha_Odd & 0.23 & 0.42 & 0.4 \\
\hline
\end{tabular}

The increase in $R^{2}$ of backscattering coefficients $\left(\sigma^{\circ}{ }_{\mathrm{RH}}, \sigma^{\circ} \mathrm{RV}\right)$ and $\mathrm{g}_{0}$ with the crop growth indicates that the radar return signal sensitivity to the paddy crop covered over agricultural fields is proportionally with biomass of the crop. Since the Stokes classical parameters (excluding $\mathrm{g}_{0}$ ) and Stokes child parameters are dependent on the structure and orientation of the target, these parameters have shown higher correlation during booting (vertically oriented) than the grain filling stage (distributed in both horizontal and vertical directions). The degree of polarization (m) has shown $\mathrm{R}^{2}$ of 0.52 on 16 Aug 2015 due to its strict vertical orientation and it has decreased to 0.05 on 10
Sep 2015 due to the increase in randomness of plant structure which leads to multiple scattering of radar signal. The counter part of "m", volume component, has shown quite opposite scenario to LAI, R ${ }^{2}$ of 0.57 on 10 Sep and 0.37 on 16 Aug 2015. It has also been observed that the volume component is more sensitive to LAI than the even bounce and odd bounce generated from $m-\delta, m-\chi$ and $m-\alpha$ space decompositions in both the crop growth stages. This analysis has clearly indicates that the sensitivity of parameters generated from RISAT-1 hybrid polarimetric SAR data is also depends on the change in plant structure due to crop growth. The RV backscatter and volume component have shown good correlation with LAI in both the paddy crop growing stages because of RV backscatter coupling with vertically oriented components of paddy and volume component is sensitive to the water content present in the plant. Since the $\mathrm{g}_{0}$ indicates the total backscatter scattering, which is having the information of both crop and underneath soil characteristics, is not suitable to retrieve any crop or soil parameters theoretically and the $\mathrm{R}^{2}$ of 0.35 has confirmed this. Several attempts have been made to investigate the potential of backscattering coefficients and polarimetric parameters for LAI estimation using empirical approach for a basic step towards paddy crop biophysical parameters retrieval.

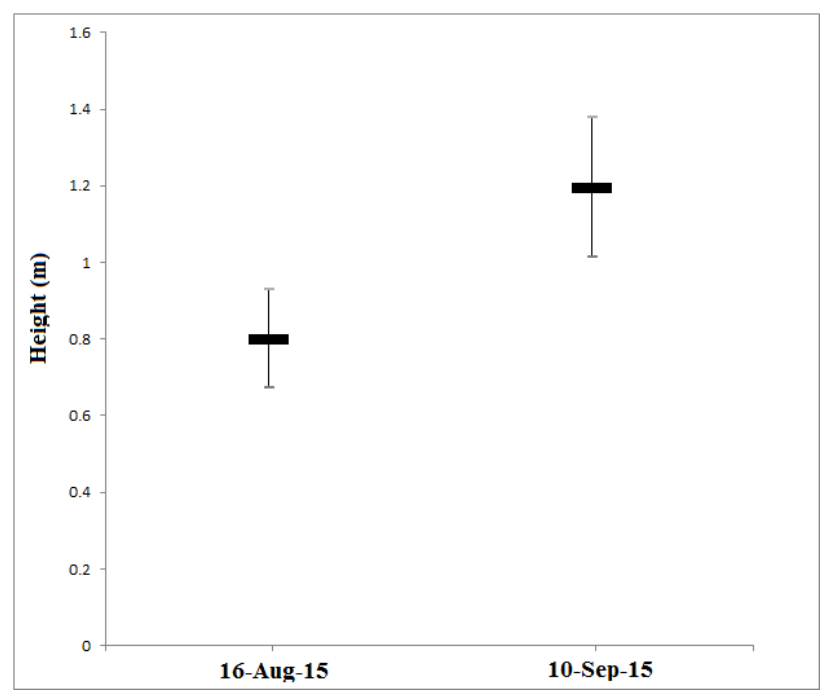

Figure 3. The range of plant heights observed from the 17 farmers' fields during the both campaigns

\subsection{Empirical analysis}

Regression analysis was carried out to develop the relationships between backscattering coefficients and polarimetric parameters (even bounce, odd bounce and volume component) generated from $\mathrm{m}-\delta, \mathrm{m}-\chi$ and $\mathrm{m}-\alpha$ space decompositions in several combinations with LAI of paddy crop. The coefficient of determination, $\mathrm{R}^{2}$, of 0.63 has observed for the obtained relationship to estimate LAI using backscattering coefficients $\left(\sigma^{\circ}{ }_{\mathrm{RH}}\right.$ and $\left.\sigma^{\circ}{ }_{\mathrm{RV}}\right)$, which is given in Equation 16. It shows that the influence of plant structure on backscattering coefficients has controlling the accuracy of the developed model.

$L A I=A+\left(B \times \sigma_{R H}^{o}\right)-\left(C \times \sigma_{R V}^{o}\right)$

Four more models have been attempted to investigate the sensitivity of polarimetric parameters (even bounce, odd bounce and volume component) generated from $m-\delta, m-\chi$ and $m-\alpha$ 
space decompositions to LAI. The developed models are in the form as given in Equation 17.

$$
L A I=A+(B \times \text { Even })+(C \times \text { Odd })+(D \times \text { Volume })
$$

In this case, it has been identified that the polarimetric parameters (even bounce, odd bounce and volume component) are more suitable to retrieve LAI of paddy crop than the backscattering coefficients. The $\mathrm{m}-\delta$ space decomposition parameters have observed $\mathrm{R}^{2}$ of 0.74 . The $\mathrm{m}-\alpha$ space decomposition has given the $\mathrm{R}^{2}$ of 0.76 , which is better than the $\mathrm{m}-\delta$ space decompositions. And $\mathrm{m}-\chi$ space decomposition has observed the highest $\mathrm{R}^{2}$, highest $\mathrm{F}$ and lowest SEE of 0.79 , 37.73 and 0.3 respectively indicates that $\mathrm{m}-\chi$ technique derived parameters may increase the accuracy of models to retrieve the LAI of paddy crop. The proper use of relative change in magnitude as well as phase of the return horizontal and vertical polarized signals in $\mathrm{m}-\chi$ space decomposition makes it superior to retrieve crop biophysical parameters from multi-temporal dataset than the other space decompositions $(m-\delta$ and $m-\alpha)$. The scatter plot of in-situ LAI and estimated LAI using backscattering coefficients and polarimetric parameters (even bounce, odd bounce and volume component) generated from $\mathrm{m}$ $\chi$ space decomposition are given in Fig. 4.

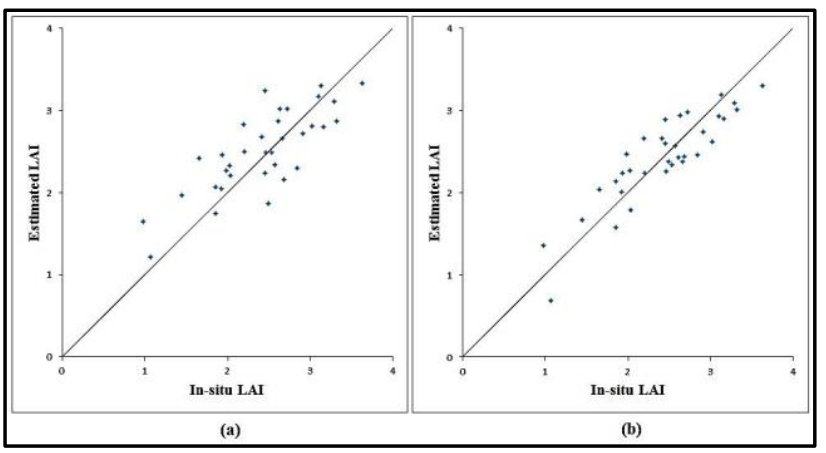

Figure 4. Scatter plot of in-situ LAI and estimated LAI (with 34 samples) using (a) backscattering coefficients and (b) even bounce, odd bounce and volume component derived using $\mathrm{m}-\chi$ space decomposition; Line indicates the 1:1 line

\begin{tabular}{|c|c|c|c|c|c|c|c|c|c|c|}
\hline \multirow{2}{*}{$\begin{array}{c}\text { S.No. } \\
1\end{array}$} & \multicolumn{5}{|c|}{$\begin{array}{c}\text { Hybrid polarimetric RISAT-1 SAR parameters used for LAI } \\
\text { retrieval }\end{array}$} & \multirow{2}{*}{$\begin{array}{l}\# \\
34\end{array}$} & \multirow{2}{*}{$\frac{\mathbf{R}^{2}}{0.63}$} & \multirow{2}{*}{$\frac{\text { SEE }}{0.39}$} & \multirow{2}{*}{$\begin{array}{c}\mathbf{F} \\
26.36\end{array}$} & \multirow{2}{*}{$\begin{array}{c}\begin{array}{c}\text { Significance } \\
\text { of } \mathbf{F}\end{array} \\
2.05 \mathrm{E}-07\end{array}$} \\
\hline & $\sigma_{\mathrm{RH}}^{\circ}$ & $\sigma_{\mathrm{RV}}^{\circ}$ & - & - & - & & & & & \\
\hline 2 & $\sigma^{\circ}{ }_{\mathrm{RH}}$ & Volume & - & - & - & 34 & 0.63 & 0.39 & 26.31 & $2.09 \mathrm{E}-07$ \\
\hline 3 & $\sigma_{\mathrm{RV}}^{\circ}$ & Volume & - & - & - & 34 & 0.61 & 0.4 & 23.66 & 5.77E-07 \\
\hline 4 & $\sigma_{\mathrm{RH}}^{\circ}$ & $\sigma_{\mathrm{RV}}^{\circ}$ & Volume & - & - & 34 & 0.64 & 0.39 & 17.40 & $9.83 \mathrm{E}-07$ \\
\hline 5 & m- $\delta$ Even & $\mathrm{m}-\delta \_$Odd & Volume & - & - & 34 & 0.74 & 0.34 & 27.83 & $8.34 \mathrm{E}-09$ \\
\hline 6 & $\mathrm{~m}-\chi$ Even & $\mathrm{m}-\chi$ Odd & Volume & - & - & 34 & 0.79 & 0.3 & 37.73 & $2.64 \mathrm{E}-10$ \\
\hline 7 & m- $\alpha \_$Even & m- $\alpha \_$Odd & Volume & - & - & 34 & 0.76 & 0.32 & 32.02 & $1.76 \mathrm{E}-09$ \\
\hline 8 & $\sigma_{\mathrm{RH}}^{\circ}$ & m- $\chi$ _Even & m- $\chi$ _Odd & Volume & - & 34 & 0.80 & 0.3 & 29.46 & $7.73 \mathrm{E}-10$ \\
\hline 9 & $\sigma_{\mathrm{RV}}^{\circ}$ & m- $\chi$ _Even & $\mathrm{m}-\chi \_$Odd & Volume & - & 34 & 0.79 & 0.3 & 27.41 & $1.75 \mathrm{E}-09$ \\
\hline 10 & $\sigma^{\circ}{ }_{\mathrm{RH}}$ & $\sigma^{\circ} \mathrm{RV}$ & m- $\chi$ _Even & m- $\chi$ _Odd & Volume & 34 & 0.8 & 0.3 & 22.8 & $4.44 \mathrm{E}-09$ \\
\hline
\end{tabular}

Since the volume component has been identified as more sensitive towards LAI of paddy than the even bounce and odd bounce generated from $\mathrm{m}-\delta, \mathrm{m}-\chi$ and $\mathrm{m}-\alpha$ space decompositions during the both crop growing stages. It has also made an attempt to develop the empirical models for LAI estimation using backscattering coefficients in combination with volume component. The models developed using RH backscatter with volume component (model 2) and RV backscatter with volume component (model 3) has given $\mathrm{R}^{2}$ of 0.63 and 0.61 respectively. Although individually the RV backscatter and volume component has shown high coefficient of determination of 0.6 and 0.57 respectively, it has been observed that there is no improvement of $\mathrm{R}^{2}$ by adding volume component with backscattering coefficient. Even the use of $\mathrm{RH}$ and $\mathrm{RV}$ backscattering coefficients with volume component (model 4) for LAI estimation, has given $\mathrm{R}^{2}$ of 0.64 . The attempted empirical models and the corresponding observed coefficient of determination are given in the Table 3 . It is also made an attempt by including the backscattering coefficients $\left(\sigma^{\circ}{ }_{\mathrm{RH}}\right.$ and $\sigma_{\mathrm{RV}}^{\circ}$ ) with polarimetric parameters (even bounce, odd bounce and volume component), but not observed any prominent improvement.

Individually, some of the hybrid polarimetric parameters have shown a good correlation with the LAI of paddy crop. But the models developed using such high sensitive parameters have not shown any improvement in the $\mathrm{R}^{2}$. For example, volume component alone has given $0.57 \mathrm{R}^{2}$ but the inclusion of volume component with backscattering coefficients in the model 3 has not shown any improvement than the model 1 which is developed using backscattering coefficients alone. And odd bounce generated from $\mathrm{m}-\alpha$ space decomposition has shown $\mathrm{R}^{2}$ of 0.4 among even bounce and odd bounce generated from the three space decompositions towards LAI of paddy crop. But the model developed using even bounce, odd bounce and volume component generated from $\mathrm{m}-\alpha$ space decomposition has not shown the highest $\mathrm{R}^{2}$ in comparison with other space decompositions. It indicates that the polarimetric parameters may highly correlate with each other leads to no improvement in the $\mathrm{R}^{2}$. Correlation coefficient ( $\mathrm{r}$ ) has been calculated among the hybrid polarimetric parameters generated from RISAT-1 SAR data for further analysis and are given in the Fig. 5. Results have shown a high correlation of 0.99 between RV backscatter and volume component. Due to this, there is no such significant change in $\mathrm{R}^{2}$ of the models 2, 3, 4 and 9. It is also observed the correlation coefficient of 0.92 between odd bounce generated from the m- $\alpha$ space decomposition and volume component. This caused the model 7 limits to give $0.76 \mathrm{R}^{2}$. 


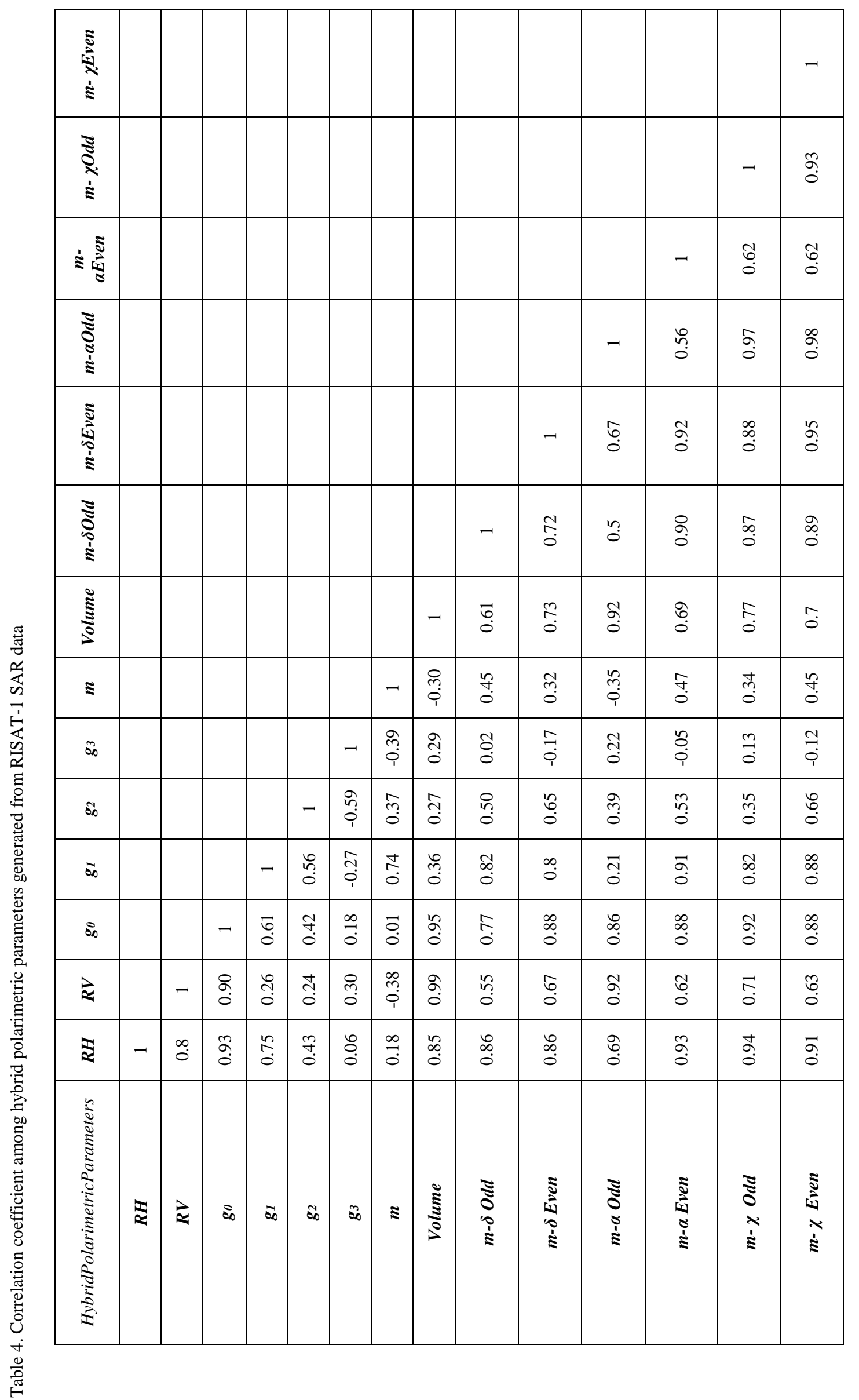


This indicates that the empirical models requires the polarimetric parameters highly sensitive towards crop biophysical parameters. Moreover, it is also necessary that those polarimetric parameters should not be highly correlated with each other, for developing the more suitable crop biophysical parameter retrieval model. Since the RH is highly correlated with even bounce and odd bounce generated from $\mathrm{m}-\chi$ space decomposition technique, the $\mathrm{R}^{2}$ of model 8 is limited to 0.8 . From this study, polarimetric parameters are identified more suitable to retrieve crop biophysical parameters than the backscattering coefficients generated from hybrid polaimetric SAR data.

\section{CONCLUSION}

Results have shown the potential use of the C-band hybrid polarimetric SAR data to retrieve LAI of paddy crop. It has been observed that the sensitivity of backscattering coefficients $\left(\sigma^{\circ} \mathrm{RH}, \sigma^{\circ} \mathrm{RV}\right)$ to LAI, is also depends on the change in plant structure due to crop growth. The sensitivity of RH polarization is increased from 0.04 on 16 Aug 2015 to 0.34 on 10 Sep 2015, caused by the portion of panicles acting as horizontal component. The sensitivity of RV polarization is also increased from 0.46 on 16 Aug 2015 to 0.55 on 10 Sep 2015, caused with the increase in plant height in vertical direction due to crop growth. Polarimetric parameters (even bounce, odd bounce and volume component) generated from $m-\delta, m-\chi$ and $m-\alpha$ space decompositions are found as more suitable to retrieve LAI of paddy crop than the backscattering coefficients. The proper use of polarimetric parameters (even bounce, odd bounce and volume component) may further increase the accuracy to estimate LAI at any crop growth stage. It is also identified $\mathrm{m}-\chi$ space decomposition generated parameters are more sensitive to the LAI of paddy. Analysis shows that the highly correlated polarimeric parameters with each other can't improve the model accuracy even though individually they are highly sensitive towards crop biophysical parameter.

\section{REFERENCES}

Baghdadi, N., Boyer, N., Todoroff, P., El Hajj, M., and Bégué, A., 2009. Potential of SAR sensors TerraSAR-X, ASAR/ENVISAT and PALSAR/ALOS for monitoring sugarcane crops on Reunion Islands. Remote Sensing of Environment, 113, pp. 1724-1738.

Brisco, B., Murnaghan, K., Wdowinski, S., and Hong, S.,2015. Evaluation of RADARSAT-2 acquisition modes for wetland monitoring applications. Canadian Journal of Remote Sensing, 41(5), pp. 431-439.doi: 10.1080/07038992.2015.1104636.

Chakraborty, M., Manjunath, K. R., Panigrahy, S., Kundu, N., andParihar, J. S., 2005. Rice crop parameter retrieval using multi-temporal, multi-incidence angle RADARSAT SAR data. ISPRS Journal of Photogrammetry Remote Sensing, 59, pp. 310-322.

Clevers, J. G. P. W., and van Leeuwen, H. J. C., 1996. Combined use of optical and microwave remote sensing data from crop growth monitoring. Remote Sensing of Environment, 55 , pp. $42-51$.

Dabboor, M., White, L., Brisco, B., and Charbonneau, F., 2015. Change detection with compact polarimetric SAR for monitoring wetlands. Canadian Journal of Remote Sensing, 41(5), pp. 408-417.doi: 10.1080/07038992.2015.1104634.

Dale, R. F., 2007. An energy-crop growth variable for identifying weather effects upon maize yields. In: Baier $\mathrm{R}$, Shaw RH, Thomson LM, Felch RE, editors. Proceedings of the Symposium on Agrometeorological Maize (Corn) Crop, 5-9 July 1976; Geneva, Switzerland.

Fontanelli, G., Paloscia, S., Zribi, M., andChahbi, A., 2013. Sensitivity analysis of X-band SAR to wheat and barley leaf area index in the Merguellil Basin. Remote Sensing Letters, 4(11), pp. 1107-1116.

Freeman, A., and Saatchi, S. S., 2004. On the detection of Faraday rotation in linearly polarized L-band SAR backscatter signatures. IEEE Transactions on Geoscience and Remote Sensing, 42(8), pp. 1607-1616.

Inoue, Y., Kurosu, T., Maneo, H., Uratsuka, S., Kozu, T., Dabrowska-Zielinska, K., and Qi, J., 2002. Season-long daily measurements of multifrequency ( $\mathrm{Ka}, \mathrm{Ku}, \mathrm{X}, \mathrm{C}$ and $\mathrm{L}$ ) and fullpolarization backscatter signatures over paddy rice field and their relationship with biological variables. Remote Sensing of Environment, 81, pp. 194-204.

Inoue, Y., Sakaiya, E., and Wang, C., 2014. Capability of Cband backscattering coefficients from high-resolution satellite SAR sensors to assess biophysical variables in paddy rice. Remote Sensing of Environment, 140, pp. 527-266.

Li, H., Perrie, W., Zhou, Y., and He, Y., 2015. Oil spill detection on the ocean surface using hybrid polarimetric SAR imagery. Science China Earth Sciences, doi: 10.1007/s11430015-5152-0.

Luckman, A., Baker, J., Kuplich, T. M., Yanasse, C. C. F., andFrery, A. C., 1997. A study of the relationship between radar backscatter and regenerating tropical forest biomass for spaceborne SAR instruments. Remote Sensing of Environment, 60(1), pp. 1-13.

Macelloni, G., Paloscia, S., Pampaloni, P., Marliani, F., andGai, M. (2001). The relationship between the backscattering coefficient and the biomass of narrow and broad leaf crops. IEEE Transactions on Geoscience and Remote Sensing, 39(4), pp. 873-884.

Paloscia, S., (1998). An empirical approach to estimating leaf area index from multifrequency SAR data. International Journal of Remote Sensing, 19(2), pp. 359-364.

Patel, P., and Srivastava, H. S., 2013. Ground truth planning for synthetic aperture radar (SAR): Addressing various challenges using statistical approach. International Journal of Advancement in Remote Sensing, GIS and Geography, 1(2), pp. $1-17$. 
Patel, P., Srivastava, H. S., Mishra, M. D., Patel, P. R., Shukla, A., Prajapati, R. P., and Shukla, A. K., 2014. Calibration of RISAT-1 fine resolution (FRS-1) mode data processed before implementation of DP software update version- 1.3.00. Scientific report: SAC/EPSA/ADVG/CVD/CALVAL/SR/07/2014, Space Applications Centre, ISRO, Ahmedabad, India.

Patel, P., Srivastava, H. S., andNavalgund, R. R., 2006. Estimating wheat yield: An approach for estimating number of grains using cross-polarized Envisat-1 ASAR data. Proceedings of SPIE, 6410, pp. 1-12.

Patel, P., Srivastava, H. S., andNavalgund, R. R., 2009. Use of synthetic aperture radar polarimetry to characterize wetland targets of Keoladeo National Park, Bharatpur, India. Current Science, 97(4), pp. 529-537.

Raney, R. K., 2007. Hybrid-polarity SAR architecture. IEEE Transactions on Geoscience and Remote Sensing, 45(11), pp. 3397-3404.

Raney, R. K., Cahill, J. R. S., Patterson, G. W., and Bussey, D. B. J., 2012. The m-chi decomposition of hybrid dualpolarimetric radar data with application to lunar craters. Journal of Geophysical Research, doi:10.1029/2011JE003986.

Santi, E., Fontanelli, G., Montomoli, F., Brogioni, M., Macelloni, G.,Paloscia, S., Penttinato, S., andPampaloni, P. (2012). The retrieval and monitoring of vegetation parameters from COSNO-SkyMed images. In IEEE International Geoscience and Remote Sensing Symposium (IGARSS), 22-27 July 2012; Munich, pp. 7031-7034.

Sivasankar, T., Srivastava, H. S., Sharma, P. K., Kumar, D., and Patel, P., (2015). Study of hybrid polarimetric parameters generated from RISAT-1 SAR data for various land cover targets. International Journal of Advancement in Remote Sensing, GIS and Geography, 3(1), pp. 32-42.

Srivastava, H. S., Patel, P., Manchada, M. L., andAdiga, S., 2003. Use of multiincidence angle RADARSAT-1 SAR data to incorporate the effect of surface roughness in soil moisture estimation. IEEE Transactions on Geoscience and Remote Sensing, 41(7), pp. 1638-1640.

Srivastava, H. S., Patel, P., Sharma, Y., andNavalgund, R. R., 2007. Detection and mapping of forested areas using SAR interferometry technique. International Journal of Geoinformatics, 3(2), pp. 1-10.

Stokes, G. G., 1852. On the composition and resolution of streams of polarized light from different sources. Transactions on Cambridge Philosophical Society, 9, pp. 399-416.

Turkar, V., De, S., Ponnurangam, F. F., Deo, R., Rao, Y. S., and Das, A., 2013. Classification of RISAT-1 hybrid polarmetric data for various land features. Asia-Pacific Conference on Synthetic Aperture Radar (APSAR), 23-27 Sept. 2013; Tsukuba, pp. 494-497.
Ulaby, F. T., Allen, C. T., and Eger III, G., 1984. Relating the microwave backscattering coefficient to leaf area index. Remote Sensing of Environment, 14, pp. 113-133.

Uppala, D., Kothapalli, R. V., Poloju, S., Mullapudi, S. S. V. R., andDadhwal, V. K., 2015. Rice crop discrimination using single date RISAT-1 hybrid (RH, RV) polarimetric data. Photogrammetric Engineering \& Remote Sensing, 81(7), pp. 557-563. 